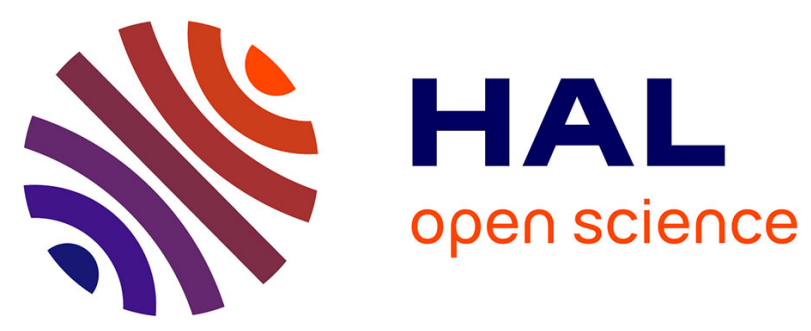

\title{
A BAR domain-mediated autoinhibitory mechanism for RhoGAPs of the GRAF family
}

Alexander Eberth, Richard Lundmark, Lothar Gremer, Radovan Dvorsky, Katja T Koessmeier, Harvey T Mcmahon, Mohammad Reza Ahmadian

\section{- To cite this version:}

Alexander Eberth, Richard Lundmark, Lothar Gremer, Radovan Dvorsky, Katja T Koessmeier, et al.. A BAR domain-mediated autoinhibitory mechanism for RhoGAPs of the GRAF family. Biochemical Journal, 2008, 417 (1), pp.371-377. 10.1042/BJ20081535 . hal-00479075

\section{HAL Id: hal-00479075 https://hal.science/hal-00479075}

Submitted on 30 Apr 2010

HAL is a multi-disciplinary open access archive for the deposit and dissemination of scientific research documents, whether they are published or not. The documents may come from teaching and research institutions in France or abroad, or from public or private research centers.
L'archive ouverte pluridisciplinaire HAL, est destinée au dépôt et à la diffusion de documents scientifiques de niveau recherche, publiés ou non, émanant des établissements d'enseignement et de recherche français ou étrangers, des laboratoires publics ou privés. 


\section{A BAR domain-mediated autoinhibitory mechanism for RhoGAPs of the GRAF family}

Alexander Eberth ${ }^{1 \S}$, Richard Lundmark ${ }^{2 \$}$, Lothar Gremer ${ }^{1,3}$, Radovan Dvorsky ${ }_{1}^{1}$, Katja T. Koessmeier ${ }^{1}$, Harvey T. McMahon ${ }^{2}$ and Mohammad Reza Ahmadian ${ }^{1 *}$

${ }^{1}$ Institute of Biochemistry and Molecular biology II, Heinrich Heine University Medical Center, Universitätsstrasse 1, 40225 Düsseldorf, Germany; ${ }^{2}$ Medical Research Council Laboratory of Molecular Biology, Hills Road, Cambridge CB2 2QH, United Kingdom; ${ }^{3}$ Max-Planck Institute of molecular Physiology, Department Structural Biology, Otto-HahnStrasse 11, 44227 Dortmund, Germany.

Address correspondence to: Tel.: +49-211-81-12384; Fax: +49-211-81-12726; e-mail: reza.ahmadian@uni-duesseldorf.de

\section{Footnotes:}

$\S$ Present Address: Division of Structural Biology, Helmholtz Centre for Infection Research, Inhoffenstrasse 7, D-38124 Braunschweig, Germany

\$ Present Address: Medical Biochemistry and Biophysics, Umeå University, 90187 Umeå, Sweden

Running title: Autoinhibitory BAR domain for RhoGAPs

Abbreviations: BAR, Bin/Amphiphysin/Rvs; DH, Dbl homology; GAP, GTPase activating protein; GRAF1, GTPase-regulator associated with focal adhesion kinase-1; OPHN1, Oligophrenin-1; PH, Pleckstrin homology; SH3, Src homology 3

Key words: BAR, GAP, GTP-hydrolysis, GTPase reaction, Rho protein family, autoregulation, autoinhibited state 


\section{ABSTRACT}

The BAR (Bin-Amphiphysin-Rvs) domain defines an emerging superfamily of proteins implicated in fundamental biological processes by sensing and inducing membrane curvature. We identified a novel autoregulatory function for the BAR domain of two related GTPase activating proteins (GAPs) of the GRAF subfamily. We demonstrate that the N-terminal fragment of these GAPs including the BAR domain interacts directly with the GAP domain and inhibits its activity. Analysis of various BAR- and GAP domains revealed that the BAR domain-mediated inhibition of these GAPs function is highly specific. These GAPs, in their autoinhibited state, are able to bind and tubulate liposomes in vitro, and to generate lipid tubules in cells. Taken together, we identified BAR domains as cis-acting inhibitory elements that very likely mask the active sites of the GAP domains and thus prevent downregulation of Rho proteins. Most remarkably, these BAR proteins represent a dual-site system with separate membrane tubulation and GAP inhibitory functions that operate simultaneously. 


\section{INTRODUCTION}

Members of the Rho family of small guanine nucleotide-binding proteins are key regulatory molecules that couple changes in the extracellular environment to intracellular signal transduction. They act as intracellular molecular switches by cycling between active (GTPbound) and inactive (GDP-bound) states [1]. Activation of Rho proteins results in their association with effector molecules that subsequently activate a wide variety of downstream signaling cascades and regulate many thus important processes in all eukaryotic cells including motility and endocytic trafficking [2]. The activity of Rho proteins - at a specific time and at a specific site in the cell - is strictly controled by three classes of regulatory proteins, the guanine nucleotide dissociation inhibitors (GDI), the guanine nucleotide exchange factors (GEFs) and the GTPase activating proteins (GAPs) [1]. These regulators safeguard two distinct cycles, membrane/cytosol partition of the Rho proteins and exchange/hydrolysis of the bound nucleotide.

The GTP-hydrolysis reaction is a fundamental process in living cells and represents an important timer in intracellular processes. The rate of Rho protein-mediated GTP hydrolysis is intrinsically slow. Direct interaction with GAPs specific for Rho proteins accelerates the reaction by several orders of magnitude [3]. The RhoGAP functions are critical for the termination of signal transduction [4]. Thus, mutations in genes encoding GAPs of the Rho proteins have drastic consequences and underlie several human diseases. OPHN1

(Oligophrenin-1) mutations frequently cause X-linked mental retardation that is associated with cerebellar hypoplasia [5]. Another GAP, that regulates endocytosis via the CLIC/GEEC pathway [6] and has been implicated as a tumor suppressor gene of acute myelogenous leukaemia and myelodysplastic syndrome is GRAF1 (GTPase-regulator associated with focal adhesion kinase-1) [7]. These RhoGAPs together with PSGAP [8] and GRAF3 (R. Lundmark, unpublished data) constitute a subfamily of structurally related regulatory proteins. They share an N-terminal Bin-Amphiphysin-Rvs-like (BAR-like) domain, followed by a pleckstrin homology (PH) domain and a RhoGAP-related domain (Figure 1 A). Nadrin (Rich1, ARHGAP17) has also similar architectur but lacks the central PH domain between the BAR and the GAP domain [9]. The BAR domain superfamily of proteins have emerged as important players in membrane remodeling processes (www.bar-superfamily.org). These domains dimerize to sense and often to induce membrane curvature [10-12]. In addition, the BAR domain of Arfaptin2/POR1 has been reported to bind differentially to ADP-ribosylation factors and Rac1 [13].

While the molecular mechanisms of Rho protein regulation by GAPs are well characterized [4], our understanding of the GAP regulation itself is an open and challenging issue. Recently, we have found that the N-terminal region of OPHN1 seems to effect its GAP function and suggested that this part of the protein itself could act as a regulator of the GAP activity either by an autoinhibitory mechanism or by binding of a second inhibitory protein [14]. In this study we investigated a potential role of the N-terminal domains of GRAF1 and OPHN1 on their GAP activities. We describe a novel function for the BAR domains of the GRAF subfamily, which inhibit the activity of the GAP domains and remodel simultaneously lipid membranes.

\section{MATERIALS AND METHODS Constructs}

Human Cdc42 (amino acids (aa) 1-178; accession number NM_001791), Rac1 (aa 1-184; M29870) and RhoA (aa 1-181; L25080) were cloned as described previously [15]. BAR-PHGAP (aa 1-572), BAR-PH (aa 1-366), PH-GAP (aa 231-572) and GAP (aa 360-572) of OPHN1 (NM_002547); BAR-PH-GAP (aa 1-576), BAR-PH (aa 1-382) and GAP (361-576) of GRAF1 (Y10388); BAR-GAP (aa 1-499), BAR (aa 1-241) and GAP (aa245-499) of 
Rich1/Nadrin (BC003259); BAR (aa 116-341) of Arfaptin2 (NM_012402), BAR (aa 1-256) of Endophilin-A1 (Q99962), GAP (aa 1250-1513) of p190RhoGĀP (M94721); GAP (aa 559882) of ABR (L19704), GAP (aa 198-439) of p50RhoGAP (NM_004308) and BAR-PH (aa 1-384) of $\beta 2$-centaurin (NP_055729) were cloned in pGEX vectors.

\section{Proteins and fluorescent nucleotides}

All proteins were produced and prepared as described [16]. Briefly, the proteins were produced as glutathione S-transferase (GST) fusion proteins in Escherichia coli BL21 Rosetta. Glutathione (GSH-) sepharose (Pharmacia, Uppsala, Sweden) was used as the first purification step. After protease cleavage of the GST-tags, the proteins were applied to a gel filtration column (Superdex 75 or 200, Pharmacia, Uppsala, Sweden) and a subsequent GSHsepharose column as the final step to obtain a purity of at least $95 \%$. Nucleotide-free GTPases as well as fluorescent nucleotide-bound GTPases were prepared, concentration and quality were determined as described [16]. Tetramethylrhodamine-conjugated GTP (tamraGTP) was synthesized according to protocols recently established in our laboratory [3, 16].

\section{Proteolytic cleavage}

Purified BAR-PH-GAP was treated with trypsin at a protease-substrate ratio of 1:4000 at room temperature up to $48 \mathrm{~h}$. Aliquots from the proteolysis reaction were withdrawn at the indicated time points. The reaction was terminated with $50 \mu \mathrm{g} / \mathrm{ml}$ leupeptin for the trypsin reaction. BAR-PH-GAP cleavage was analyzed on SDS-polyacrylamide gels.

\section{Fluorescence measurements}

The stopped-flow instrument (Applied Photophysics SX18MV, Leatherhead, UK) was routinely utilized for analysis of rapid kinetics, such as GAP-stimulated GTPase reactions (single turn-over conditions) as described [16]. All fluorescence measurements were performed in $30 \mathrm{mM}$ Tris/ $\mathrm{HCl} \mathrm{pH} 7.5,10 \mathrm{mM} \mathrm{KH}_{2} \mathrm{PO}_{4} / \mathrm{K}_{2} \mathrm{HPO}_{4} \mathrm{PH} 7.4,10 \mathrm{mM} \mathrm{MgCl} 2,50$ $\mathrm{mM} \mathrm{NaCl}$, and $3 \mathrm{mM} \mathrm{DTE}$ at $25^{\circ} \mathrm{C}$.

\section{Isothermal titration microcalorimetry}

Titration experiments were carried out at $10^{\circ} \mathrm{C}$ with the isothermal titration microcalorimeter VP-ITC system (Microcal, Northampton, MA). All protein solutions were prepared in $20 \mathrm{mM}$ Tris/HCl pH 7.5 by size exclusion chromatography. The protein concentrations in the calorimetric cell were between 50 to $400 \mu \mathrm{M}$. Injections of ligand solution $(1-3.5 \mathrm{mM})$ into the calorimetric cell were carried out at time intervals of $200 \mathrm{~s}$ with injection volumes of $8 \mu 1$. The injection volume was $8 \mu \mathrm{l}$ except for the first step $(2 \mu 1)$. The total number of injections was 60 . Spacing time between injections was $4 \mathrm{~min}$. Analysis of the experimental data was carried out with Origin 7.0 (Microcal). Binding parameters such as number of binding sites $(n)$, the association constant $\left(K_{\mathrm{a}}\right)$ and the binding enthalpy $\left(\Delta H^{\circ}, \mathrm{kcal} / \mathrm{mol}\right)$ were determined as parameters of the fitted experimental binding values.

\section{Liposome co-sedimentation assay}

Liposomes were generated from total brain lipids (FOLCH fraction I) (Sigma Aldrich) or synthetic lipids (10\% phosphatidylinositol 4,5 bisphosphate, $10 \%$ cholesterol, $40 \%$ Phosphatidylethanolamine, $40 \%$ Phosphatidylcholine (Avanti Polar Lipids) and filtered to the specified diameter as previously described [9]. Briefly, the lipid mixtures were dried under a stream of nitrogen and resolved in assay buffer before sonication to generate spherical liposomes. Liposome binding assays was essentially performed as described [10]. Briefly, proteins were incubated together with liposomes followed by centrifugation and analysis of the pellet and supernatant on SDS-PAGE gel electrophoresis. 


\section{Transfection and membrane staining}

HeLa cells were grown in DMEM media (GIBCO) supplemented with $10 \%$ foetal bovine serum, and transfected for transient protein expression using Lipofectamine 2000 (Invitrogen) according to manufacturer's instructions. For immunofluorescence analysis, HeLa cells were fixed in $3 \%$ paraformaldehyde in phosphate-buffered saline (PBS) for $15 \mathrm{~min}$ at $22^{\circ} \mathrm{C}$, then washed and blocked in PBS containing 5\% goat serum and $0.1 \%$ saponin before staining with rabbit anti-myc antibodies (Cell Signalling Technology) in 1\% goat serum, $0.1 \%$ saponin in PBS and secondary Alexa 488 conjugated anti-rabbit antibodies (Invitrogen) using standard protocols. Epifluorescence images were taken using a Zeiss Axioimager Z1 system with AxioVision software.

\section{RESULTS AND DISCUSSION \\ BAR domain a cis-acting inhibitory element}

In a previous study, we found that full-length OPHN1 showed a much weaker GAP activity compared to the GAP domain alone when overexpressed in cells [14]. To investigate a potential inhibitory mechanism for the catalytic GAP domain we purified various protein fragments of OPHN1 (Figure 1A) and determined their activities in a real-time fluorescencebased GTP hydrolysis assay $[3,16]$. The central tool of this assay is a tetramethylrhodaminelabeled GTP (tamraGTP), which is sensitive towards the active state of the Rho proteins and thus can be used to monitor not only the intrinsic but also GAP-stimulated hydrolysis reactions. In contrast to OPHN1 GAP (denoted GAP ${ }^{\mathrm{O}}$ ) and $\mathrm{PH}-\mathrm{GAP}^{\mathrm{O}}$, which were able to rapidly stimulate the intrinsic GTP-hydrolysis reaction of Cdc42 to the same extend, the GAP activity of BAR-PH-GAP ${ }^{\mathrm{O}}$ was drastically reduced (50-fold, under the condition tested here; Figure 1B). Similar results were obtained when RhoA or Rac1 were used (data not shown). We used $\mathrm{Cdc} 42$ as a model protein for all experiments since $\mathrm{GAP}^{\mathrm{O}}$ revealed the highest activity towards Cdc42 when compared to that of RhoA and Rac1 (Supplementary Figure S1 online).

To prove that the drastic reduction of the BAR-PH-GAP ${ }^{\mathrm{O}}$ activity is rather caused by specific domain-domain interaction than by protein instability or misfolding, we subjected BAR-PH$\mathrm{GAP}^{\mathrm{O}}$ to partial proteolysis. Two fragments of 24 and $22 \mathrm{kDa}$ remained stable after limited trypsin cleavage for $48 \mathrm{~h}$ (Figure $1 \mathrm{C}$; supplementary Figure $\mathrm{S} 2 \mathrm{~A}$ ). Trypsin treatment of $\mathrm{GAP}^{\mathrm{O}}$ or $\mathrm{BAR}-\mathrm{PH}^{\mathrm{O}}$, however, resulted in a complete digestion of BAR-PH ${ }^{\mathrm{O}}$ but $\mathrm{GAP}^{\mathrm{O}}$ was cleaved to a $22 \mathrm{kDa}$ fragment that remained resistant against trypsin (Supplementary Figure S2B). A comparison of the trypsin treatment of $\mathrm{GAP}^{\mathrm{O}}$ and $\mathrm{BAR}-\mathrm{PH}-\mathrm{GAP} \mathrm{P}^{\mathrm{O}}$ clearly indicated that the tryptic products of the latter cover $\mathrm{GAP}^{\mathrm{O}}$ as it retained full GAP activity (Figure 1B). Moreover, BAR-PH-GAP ${ }^{O}$ cleavage at 30 min was significantly reduced in comparison to BAR-PH ${ }^{\mathrm{O}}$, which is entirely trypsinized after 15 min (Supplementary Figure S2B). It appears that the presence of $\mathrm{GAP}^{\mathrm{O}}$ in $\mathrm{BAR}-\mathrm{PH}-\mathrm{GAP}^{\mathrm{O}}$ protects $\mathrm{BAR}-\mathrm{PH}^{\mathrm{O}}$ against trypsin digestion. These results provided a first evidence for a domain-domain interaction of OPHN1 indicating that BAR-PH-GAP ${ }^{\mathrm{O}}$ exists in a 'closed', autoinhibited state, and tryptic degradation of BAR$\mathrm{PH}^{\mathrm{O}}$ allowed the release of the autoinhibitory function.

Next we examined whether the autoinhibited state of OPHN1 can be reconstituted in trans using isolated $\mathrm{GAP}^{\mathrm{O}}$ and $\mathrm{BAR}-\mathrm{PH}^{\mathrm{O}}$. As shown in Figure $1 \mathrm{D}$, increasing amounts of BAR$\mathrm{PH}^{\mathrm{O}}$ led to an incremental inhibition of the GAP-stimulated tamraGTP hydrolysis of Cdc42, which is indicative for the direct association between $\mathrm{BAR}-\mathrm{PH}^{\mathrm{O}}$ and the GAP ${ }^{\mathrm{O}}$. An $\mathrm{IC}_{50}$ (concentration causing 50\% inhibition of GAP activity) value of $11.8 \mu \mathrm{M}$ was obtained by hyperbolic fitting of individual observed rate constants $\left(\mathrm{k}_{\mathrm{obs}}\right)$ plotted against the used BAR$\mathrm{PH}^{\mathrm{O}}$ concentrations. Addition of $\mathrm{BAR}-\mathrm{PH}^{\mathrm{O}}$ to $\mathrm{GAP}^{\mathrm{O}}$ was able to reduce the GAP activity to a level similar to that of BAR-PH-GAP ${ }^{\mathrm{O}}$. To validate this result, the equilibrium dissociation constant $\left(\mathrm{K}_{\mathrm{d}}\right)$ for the interaction between $\mathrm{GAP}^{\mathrm{O}}$ and $\mathrm{BAR}-\mathrm{PH}^{\mathrm{O}}$ was determined to be $21.3 \mu \mathrm{M}$ 
using isothermal titration calorimetry (ITC) (Figure 1E; see also supplementary Figure S3). The difference between the $\mathrm{K}_{\mathrm{i}}$ and $\mathrm{K}_{\mathrm{d}}$ values is most likely based on different temperature conditions (see Methods). In addition, a 1:1 stoichiometry was derived from the ITC titration curve for this intermolecular interaction. Based on the recent dimeric BAR and BAR-PH structures $[11 ; 18$; and references cited there], this result can also be interpreted as a 2:2 complex between BAR-PH and GAP.

In summary, our data showed that OPHN1 exists in an autoinhibited state that is characterized by physical interactions between the BAR-PH and the GAP domains. As a consequence, BAR-PH competitively interferes with complex formation between GAP domain and cognate Rho protein (Cdc42.GTP in this case) inhibiting thereby the stimulation of the GTPhydrolysis reaction. This result adds a novel function to the rapidly expanding knowledge of BAR protein superfamily.

\section{A conserved autoregulatory mechanism for the GRAF subfamily}

GRAF proteins (GRAF1, 2, 3) are BAR domain-containing RhoGAPs within the same family as OPHN1 (Figure 1A). That is why we have also examined, the impact of the corresponding GRAF1 BAR-PH (BAR-PH ${ }^{\mathrm{G}}$ ) on the activity of GAP ${ }^{\mathrm{G}}$. Similar to OPHN1, also BAR-PH$\mathrm{GAP}^{\mathrm{G}}$ resided in an autoinhibited state. Its activity in stimulating GTP-hydrolysis of Cdc42 was far below GAP ${ }^{\mathrm{G}}$ alone (Figure $2 \mathrm{~A}$ ). In addition, $\mathrm{GAP}^{\mathrm{G}}$ activity was also inhibited in trans by mixing rapidly $\mathrm{BAR}-\mathrm{PH}^{\mathrm{G}}$ and $\mathrm{GAP}^{\mathrm{G}}$ in stopped-flow experiments although higher concentrations were required to achieve an equal inhibition compared to OPHN1 (data not shown). The observed lower efficiency of GRAF1 inhibition is probably caused by lower binding affinity of $\mathrm{BAR}-\mathrm{PH}^{\mathrm{G}}$ for its $\mathrm{GAP}^{\mathrm{G}}$ domain as a quantitative analysis of BAR-PH ${ }^{\mathrm{G}}$ mediated $\mathrm{GAP}^{\mathrm{G}}$ inhibition revealed an $\mathrm{IC}_{50}$ value of $43.6 \mu \mathrm{M}$ (data not shown). Titration of BAR-PH ${ }^{\mathrm{G}}$ with $\mathrm{GAP}^{\mathrm{G}}$ in ITC yielded an approximate $\mathrm{K}_{\mathrm{d}}$ value of $111 \mu \mathrm{M}$ for this bimolecular interaction (supplementary Figure S3 online). Our data showed that OPHN1 and GRAF1 adopted an autoinhibited state that is provided by an interaction between the BAR$\mathrm{PH}$ and the GAP domains. This novel mechanism is general for proteins in this subfamily. In contrast to the BAR-PH-containing GRAF subfamily members, stopped-flow experiments with Nadrin BAR-GAP (BAR-GAP ${ }^{\mathrm{N}}$ ) revealed about the same activity as measured for the isolated GAP ${ }^{\mathrm{N}}$ domain (Figure 2A). Even a 50-fold molar excess of the isolated $\mathrm{BAR}^{\mathrm{N}}$ above the GAP ${ }^{\mathrm{N}}$ concentration did not inhibit the GAP-stimulated tamraGTP hydrolysis at all (Figure 2A). These results led us to the conclusion that $\mathrm{BAR}^{\mathrm{N}}$ is unable to inactivate $\mathrm{GAP}^{\mathrm{N}}$ and thus may not be directly involved in the regulation of Nadrin GAP activity. It is also important to note that Nadrin is not as efficient as compared to OPHN1 and GRAF (Figure 2A). Comparison with other members of the Rho family revealed that Nadrin exhibited the highest GAP activity for Racl (data not shown). Using tamraGTP hydrolysis by Rac1 and $\mathrm{GAP}^{\mathrm{N}}, \mathrm{BAR}^{\mathrm{N}}$ and BAR-GAP ${ }^{\mathrm{N}}$ (Supplementary Figure S4) we could show that Nadrin GAP activity is not regulated by the N-terminal BAR domain.

There are two possible explanations for this finding. The first and perhaps most probable explanation for the lack of BAR-mediated regulation of Nadrin GAP activity may rely on the nature of the $\mathrm{BAR}^{\mathrm{N}}$ structure that is different from the classical BAR domains $[10 ; 11 ; 17]$. Nadrin belongs to a subclass of BAR domains that contain an N-terminal amphipathic helix (called N-BAR), which works as functional unit to promote dimerization and membrane curvature generation [18;19]. It is also necessary to note that Nadrin lacks the central PH domain in contrast to GAPs of the GRAF subfamily (Figure 1A). Although the PH-GAP ${ }^{\mathrm{O}}$ showed no significant change in GAP-stimulated hydrolysis (Figure 1B, 2A) the possibility that the PH domain might be important for autoinhibition should not be excluded. The isolated BAR domain of OPHN1 or GRAF1 could shed light on this subject but we were not successful so far in preparing a stable BAR domain of OPHN1 or GRAF1. 


\section{BAR-mediated GAP inhibition is highly specific}

After we have identified the BAR domain of OPHN1 and GRAF1 as an autoinhibitory element that potently suppresses the GAP activity of these regulators, we next examined if such an inhibitory activity is interchangeable among other BAR domains. To address this question we determined the $\mathrm{k}_{\mathrm{obs}}$ values of the GAP-stimulated tamraGTPase hydrolysis reaction of $\mathrm{Cdc} 42$ in the presence of various BAR domains including OPHN1, GRAF1, Nadrin, Amphiphysin, Arfaptin-2 and Endophilin-A1. As shown in Figure 2B, GAP ${ }^{\mathrm{O}}$ activity is exclusively inhibited by a 50 -fold molar excess of the $\mathrm{BAR}-\mathrm{PH}^{\mathrm{O}}$. Even the closely homologous BAR-PH ${ }^{\mathrm{G}}$ was not able to reduce the GAP ${ }^{\mathrm{O}}$ activity. Similarly BAR domains were not able to bind to GAP ${ }^{\mathrm{G}}$ and inhibit its stimulatory GTPase activity except the BAR$\mathrm{PH}^{\mathrm{G}}$ and $\mathrm{BAR}-\mathrm{PH}^{\mathrm{O}}$ (Figure $2 \mathrm{C}$ ) that, most remarkably, appeared to be a more potent inhibitor than BAR-PH ${ }^{\mathrm{G}}$ itself. This result is consistent with higher binding affinity of $\mathrm{BAR}-\mathrm{PH}^{\mathrm{O}}$ for the $\mathrm{GAP}^{\mathrm{O}}$ domain and indicates that OPHN1 and GRAF1 autoregulation operates through a similar molecular mechanism.

Another issue we addressed was whether the BAR binding site of the GAP domain is specific among different GAPs for the Rho family. Therefore, we measured stimulation of Cdc42mediated tamraGTP hydrolysis by the catalytic domain of p50GAP, p190GAP and ABR in the absence and in the presence of BAR-PH ${ }^{\mathrm{O}}$. Figure $2 \mathrm{D}$ shows that the activity of these GAPs is not affected at all and emphasizes that the BAR domain-mediated autoinhibition of OPHN1 is highly specific. These data also indicate that the BAR/GAP interaction utilizes signatures, which are selective for the GRAF subfamily of GAPs.

\section{Simultaneous dual-site of action of the BAR domain}

Next step of the investigation was to examine the impact of lipid membrane on the autoinhibited state of these GAPs. We repeated the real-time fluorescence measurements of the tamraGTPase reaction of Cdc42 in the presence of liposomes and lipid membranes of different size. Representative data are shown in Figure 3A. It is evident that the activity of the autoinhibited BAR-PH-GAP protein was not altered at all. This prompted us to address the question whether the autoinhibited state of OPHN1 influences membrane binding and tubulating abilities of the BAR domain, which was reported previously [10]. Using a liposome co-sedimentation assay, we found that the $\mathrm{GAP}^{\mathrm{O}}$ domain indeed could be cosedimented with the membranes if $\mathrm{BAR}-\mathrm{PH}^{\mathrm{O}}$ was present, again showing the transinteraction. The robust binding of $\mathrm{BAR}-\mathrm{PH}^{\mathrm{O}}$ to liposomes both in the absence and presence of $\mathrm{GAP}^{\mathrm{O}}$ (Figures 3B, 3C) suggests that the trans-interaction between these domains did not inhibit the membrane binding ability of the $\mathrm{BAR}-\mathrm{PH}^{\mathrm{O}}$. GAP ${ }^{\mathrm{O}}$ was also able to cosediment with BAR-PH ${ }^{\mathrm{G}}$ but to a much lower extent compared to BAR-PH ${ }^{\mathrm{O}}$ (Figure 3C). This is in agreement with data described above and again indicates that $\mathrm{BAR}-\mathrm{PH}^{\mathrm{G}}$ exhibits a much weaker GAP inhibitory effect. Similar data were obtained using $\beta 2$ centaurin BAR-PH as control. To further investigate whether membrane binding is influenced in the context of autoinhibited protein, we compared the liposome binding activity of $\mathrm{BAR}-\mathrm{PH}^{\mathrm{O}}$ and the $\mathrm{BAR}-$ $\mathrm{PH}_{-G A P}{ }^{\mathrm{O}}$. As shown in Figure 3D-3E, instead of acting inhibitory, the presence of the GAP domain yielded an even higher amount of BAR-PH-GAP ${ }^{\mathrm{O}}$ bound to the liposomes as compared to that of $\mathrm{BAR}-\mathrm{PH}^{\mathrm{O}}$. This result shows that the presence of the GAP domain does not perturb membrane binding but may facilitate the interaction of the BAR domain with the lipid membrane. Moreover, BAR-PH-GAP ${ }^{\mathrm{O}}$ was also able to generate lipid tubules when incubated together with liposomes (Figure $3 \mathrm{~F}$ ) and to localize to membrane tubules when overexpressed in cells (Figure $3 \mathrm{G}$ ). These data show that $\mathrm{BAR}-\mathrm{PH}^{\mathrm{O}}$ domain was unaffected in its membrane binding and tubulating activity regardless of its interaction with the C-terminal GAP domain. BAR domain represents a dual-site system, which simultaneously interacts with the GAP domain and the lipid vesicles. In addition, interaction between GAP and BAR domain seems to potentiate the BAR-mediated ability of membrane binding and remodelling. 


\section{CONCLUSIONS}

BAR domains recently took centre stage in the science because of their function as membrane curvature sensing and stabilizing protein modules $[11 ; 17 ; 19-21]$. Our work has uncovered a novel autoinhibitory function for BAR domain-containing RhoGAPs of the GRAF subfamily. This is a stringent control mechanism to suppress efficiently and locally the GAP activity of GRAF proteins. Similar autoregulatory modes have been implicated for other RhoGAPs, including DLC1 and p50RhoGAP. Whereas the mechanism of the autoinhibitory domain remained unknown for DLC1 [22] an N-terminal SEC14/BCH domain has been shown to be essential for the regulation of the GAP activity of p50RhoGAP [23].

This study provided first evidence for dual-site action of a BAR domain that exhibits simultaneously membrane and protein binding capabilities with the latter being an inhibitory function on GAPs of the GRAF subfamily. One of the most crucial questions of how the BAR domain of GRAF1 or OPHN1 binds to the GAP domain and inhibits its activity (Figure 4A) remains still a subject for further research. Biochemical data from this and other studies along with the structural determination of BAR domain-containing proteins have shown that BARlike domains form elongated, banana-shaped, $\alpha$-helical homodimers in antiparallel orientation [11]. Therefore, intramolecular interactions of a monomer or of a parallel dimer and even an intermolecular head-to-tail dimer (Figure 4B) can be excluded. The fact that the BAR domain directly inhibits GAP-stimulated GTPase reaction of Rho proteins supports the notion that it may bind to the Rho-binding region of the GAP domain and thus masks its catalytic residues including the arginine finger [24]. Moreover, it has been reported that BAR dimers bind membranes electrostatically through their positively charged concave surface [10]. But simultaneous interactions of the BAR domain of OPHN1 with the membrane and the GAP domain rather suggests that the GAP domain may bind to the convex surface of a bananashaped homodimer of the BAR domain. Accordingly, an intramolecular interaction between the domains of one protein or an intermolecular interaction between the domains across the two proteins or a transmolecular interaction of one GAP domain and two BAR domains are three alternative symmetrical binding modes of how these domains approach one another (Figure 4C). The latter model of an autoinhibited state supports the idea of GAP-induced stabilization of the dimerization state of the BAR domain.

The role of the BAR domain, in conjunction with other domains including the PH domain, is to localize the dormant autoinhibited GAP protein to the membrane. As we know now, this is not sufficient to release the GAP domain and induce the GAP activity. Thus, an obvious next step of the investigation is to understand the release mechanism of the autoinhibited state of these GAPs. Additional interactions are likely to displace the autoinhibiting BAR domain and to release the GAP domain for specific binding to an adjacent Rho protein at the membrane. This will drive the progression of cellular processes in which GAPs of the GRAF subfamily are required including dendritic spine morphogenesis and axon growth [25]. Identification of functional modules that inhibit the GAP activity, however, was an important first step towards elucidating underlying cellular mechanism of these critical regulators. 


\section{ACKNOWLEDGEMENTS}

We are grateful to Pierre Billuart, Gary Doherty and Linda van Aelst for providing cDNA and plasmids; to Patricia Stege and Michael Schenker for expert technical assistance, to Mamta Jaiswal for critical reading of the mansucript. This work was supported by the Forschungskommission der Medizinischen Fakultät der Heinrich-Heine-Universität Düsseldorf, the Deutsche Forschungsgemeinschaft (AH 92/3-1 und AH 92/5-1), the Volkswagen-Stiftung (I/82 678), the Swedish research council and P.E. Lindahls foundation, Medical Faculty, Umeå University for financial supports. MRA gratefully thanks Alfred Wittinghofer and Bernd Nürnberg for continuous support. We apologize for citation of reviews instead of original articles due to space constraints. 


\section{REFERENCES}

1 Dvorsky, R. and Ahmadian, M. R. (2004) Always look on the bright site of Rho: structural implications for a conserved intermolecular interface. EMBO Rep. 5, 11301136

2 Etienne-Manneville, S. and Hall, A. (2002) Rho GTPases in cell biology. Nature 420, $629-635$

3 Eberth, A., Dvorsky, R., Becker, C. F. W., Beste, A., Goody, R. S., and Ahmadian, M. R. (2005) Monitoring the real-time kinetics of the hydrolysis reaction of guanine nucleotide-binding proteins. Biol.Chem. 386, 1105-1114

4 Scheffzek, K. and Ahmadian, M. R. (2005) GTPase activating proteins: structural and functional insights 18 years after discovery. Cell. Mol. Life Sci. 62, 3014-3038

5 Billuart, P., Bienvenu, T., Ronce, N., des Portes, V., Vinet, M. C., Zemni, R., Crollius, H. R., Carrie, A., Fauchereau, F., Cherry, M., Briault, S., Hamel, B., Fryns, J. P., Beldjord, C., Kahn, A., Moraine, C., and Chelly, J. (1998) Oligophrenin-1 encodes a rhoGAP protein involved in X-linked mental retardation. Nature 392, 923-926

6. Lundmark, R., Doherty, G. J., Howes, M. T., Cortese, K., Vallis, Y., Parton, R. G., and McMahon, H.T. (2008) The GTPase activating protein GRAF1 regulates the CLIC/GEEC endocytic pathway. Curr.Biol. (in press)

7 Borkhardt, A., Bojesen, S., Haas, O. A., Fuchs, U., Bartelheimer, D., Loncarevic, I. F., Bohle, R. M., Harbott, J., Repp, R., Jaeger, U., Viehmann, S., Henn, T., Korth, P., Scharr, D., and Lampert, F. (2000) The human GRAF gene is fused to MLL in a unique $\mathrm{t}(5 ; 11)(\mathrm{q} 31 ; \mathrm{q} 23)$ and both alleles are disrupted in three cases of myelodysplastic syndrome/acute myeloid leukemia with a deletion 5q. Proc.Natl.Acad.Sci.U.S.A. 97, 9168-9173

8 Ren, X. R., Du, Q. S., Huang, Y. Z., Ao, S. Z., Mei, L., and Xiong, W. C. (2001) Regulation of CDC42 GTPase by proline-rich tyrosine kinase 2 interacting with PSGAP, a novel pleckstrin homology and Src homology 3 domain containing rhoGAP protein. J.Cell Biol. 152, 971-983

9 Harada, A., Furuta, B., Takeuchi, K., Itakura, M., Takahashi, M., and Umeda, M. (2000) Nadrin, a novel neuron-specific GTPase-activating protein involved in regulated exocytosis. J.Biol.Chem. 275, 36885-36891

10 Peter, B. J., Kent, H. M., Mills, I. G., Vallis, Y., Butler, P. J. G., Evans, P. R., and McMahon, H. T. (2004) BAR domains as sensors of membrane curvature: the amphiphysin BAR structure. Science 303, 495-499

11 Gallop, J. L. and McMahon, H. T. (2005) BAR domains and membrane curvature: bringing your curves to the BAR. Biochem. Soc.Symp. 72, 223-231

12 Frost, A., De Camilli, P., and Unger, V. M. (2007) F-BAR proteins join the BAR family fold. Structure 15, 751-753

13 Shin, O. H. and Exton, J. H. (2005) Assays and properties of arfaptin 2 binding to Rac1 and ADP-ribosylation factors (Arfs). Methods Enzymol. 404, 359-367 
14 Fauchereau, F., Herbrand, U., Chafey, P., Eberth, A., Koulakoff, A., Vinet, M. C., Ahmadian, M. R., Chelly, J., and Billuart, P. (2003) The RhoGAP activity of OPHN1, a new $\mathrm{F}$-actin-binding protein, is negatively controlled by its amino-terminal domain. Mol.Cell.Neurosci. 23, 574-586

15 Hemsath, L., Dvorsky, R., Fiegen, D., Carlier, M. F., and Ahmadian, M. R. (2005) An electrostatic steering mechanism of Cdc42 recognition by Wiskott-Aldrich syndrome proteins. Mol.Cell 20, 313-324

16 Hemsath, L. and Ahmadian, M. R. (2005) Fluorescence approaches for monitoring interactions of Rho GTPases with nucleotides, regulators, and effectors. Methods 37, 173-182.

17 Dawson, J. C., Legg, J. A., and Machesky, L. M. (2006) Bar domain proteins: a role in tubulation, scission and actin assembly in clathrin-mediated endocytosis. Trends Cell Biol. 16, 493-498

18 Richnau, N., Fransson, A., Farsad, K., and Aspenstrom, P. (2004) RICH-1 has a BIN/Amphiphysin/Rvsp domain responsible for binding to membrane lipids and tubulation of liposomes. Biochem.Biophys.Res.Commun. 320, 1034-1042

19 Gallop, J. L., Jao, C. C., Kent, H. M., Butler, P. J. G., Evans, P. R., Langen, R., and McMahon, T. (2006) Mechanism of endophilin N-BAR domain-mediated membrane curvature. EMBO J. 25, 2898-2910

20 Zimmerberg, J., and McLaughlin, S. (2004) Membrane curvature: how BAR domains bend bilayers. Curr.Biol. 14, R250-252

21 Habermann, B. (2004) The BAR-domain family of proteins: a case of bending and binding? EMBO Rep. 5, 250-255

22 Healy, K. D., Hodgson, L., Kim, T. Y., Shutes, A., Maddileti, S., Juliano, R. L., Hahn, K. M., Harden, T. K., Bang, Y. J., and Der, C. J. (2008) DLC-1 suppresses non-small cell lung cancer growth and invasion by RhoGAP-dependent and independent mechanisms. Mol. Carcinog. 47, 326-337

23 Moskwa, P., Paclet, M. N., Dagher, M. C., and Ligeti, E. (2005) Autoinhibition of p50 Rho GTPase-activating protein (GAP) is released by prenylated small GTPases. J.Biol.Chem. 280, 6716-6720

24 Longenecker, K. L., Zhang, B. L., Derewenda, U., Sheffield, P. J., Dauter, Z., Parsons, J. T., Zheng, Y., and Derewenda, Z. S. (2000) Structure of the BH domain from graf and its implications for Rho GTPase recognition. J.Biol.Chem. 275, 38605-38610

25 Govek, E. E., Newey, S. E., Akerman, C. J., Cross, J. R., Van, d., V, and Van Aelst, L. (2004) The X-linked mental retardation protein oligophrenin-1 is required for dendritic spine morphogenesis. Nat.Neurosci. 7, 364-372 


\section{FIGURE LEGENDS}

Figure 1 BAR-mediated autoinhibition of OPHN1 GAP activity. (A) Schematic representation of the BAR domain-containing regulators of Rho proteins and constructs used in this study. Abbreviations not explained in the text are: $\mathrm{P}$, proline-rich; $\mathrm{pQ}$, polyglutamine; SH3, Src homology 3; STP, serine-threonine-proline-rich. (B) In contrast to GAP ${ }^{\mathrm{O}}$ or PH$\mathrm{GAP}^{\mathrm{O}}$, the BAR-PH-GAP ${ }^{\mathrm{O}}$ represents an autoinhibited state of OPHN1, as it exhibited a strongly reduced GAP activity towards Cdc42.tamraGTP $(0.2 \mu \mathrm{M})$. The concentration of the GAP proteins was $1 \mu \mathrm{M}$. The inset shows the complete time course of the GTPase reaction in the absence (intrinsic; no GAP) or in the presence of BAR-PH-GAP. The observed rate constants $\left(\mathrm{k}_{\mathrm{obs}}\right)$ obtained by single exponential fitting of the curves were $0,0031 \mathrm{~s}^{-1}$ for the intrinsic reaction (no GAP); $0,18 \mathrm{~s}^{-1}$ for the BAR-PH-GAP $, 9,1 \mathrm{~s}^{-1}$ for the GAP $; 8,6 \mathrm{~s}^{-1}$ for the $\mathrm{PH}-\mathrm{GAP}^{\mathrm{O}}$ and $6.3 \mathrm{~s}^{-1}$ for the tryptic product of the BAR-PH-GAP ${ }^{\mathrm{O}}$. Values represent the average of at least at least five different experiments. (C) Coommassie-stained SDS-gel shows purified BAR-PH-GAP ${ }^{\mathrm{O}}$ protein before $(0 \mathrm{~h})$ and after tryptic digestion $(48 \mathrm{~h})$. M stands for marker proteins (D) Inhibition of the GAP-stimulated tamraGTP hydrolysis reaction of Cdc42 $(0.2 \mu \mathrm{M})$ was measured in the presence of $0.5 \mu \mathrm{M} \mathrm{GAP}$ and varying amounts of the BAR$\mathrm{PH}^{\mathrm{O}}$ domain $(5-100 \mu \mathrm{M})$. The $\mathrm{IC}_{50}$ value of $11.8 \mu \mathrm{M}$ was calculated by hyperbolic fitting of the binding curves. (E) Calorimetric titration of $150 \mu \mathrm{M}$ BAR-PH ${ }^{\mathrm{O}}$ with $1500 \mu \mathrm{M} \mathrm{GAP}{ }^{\mathrm{O}}$. Fitting of the isothermal curve yielded a molar ratio of 0.87 and a $K_{d}$ value of $21 \mu \mathrm{M}$.

Figure 2 Inhibitory activity of BAR domains of the OPHN1/GRAF1 BAR/GAP domains. (A) Comparison of GAP activities of different proteins from OPHN1, GRAF1 and Nadrin. All catalytic fragments of GAPs have been used at $1 \mu \mathrm{M}$ concentration and inhibitory $\mathrm{BAR}^{\mathrm{N}}$ or BAR-PH ${ }^{\mathrm{O} / \mathrm{G}}$ domains were applied at $50 \mu \mathrm{M}$ concentration. (B) Inhibitory effect of different $\mathrm{BAR}$ domain-containing proteins on $\mathrm{GAP}^{\mathrm{O}}$ activity. Concentrations have been used as in A. (C) Inhibitory effect of different BAR domain-containing proteins on $\mathrm{GAP}^{\mathrm{G}}$ activity. Concentrations have been used as in $\mathrm{A}$ and $\mathrm{B}$. (D) Influence of $\mathrm{BAR}-\mathrm{PH}^{\mathrm{O}}$ on the activity of different GAP catalytic fragments from $\mathrm{p} 50 \mathrm{RhoGAP}, \mathrm{p} 190 \mathrm{RhoGAP}$ and ABR. All $\mathrm{k}_{\text {obs }}$ values represent the average of 5-7 different experiments.

Figure 3 Simultaneous operation of membrane tubulation and GAP inhibitory functions. (A) Effect of lipid membranes on the autoinhibited state of OPHN1. Compared GAP activities of BAR-PH-GAP ${ }^{\circ}$ measured in the absence (no lip) and presence of phosphatidyl 4,5 bisphosphate-enriched liposomes (lip) and liposomes generated from total brain lipids (brain lip). Values represent the average of at least five different experiments. (BD) Coomassie-stained gels of liposome co-sedimentation assays. Indicated proteins $(4 \mu \mathrm{M})$ were incubated with liposomes (lip) or without liposomes (no lip) for $20 \mathrm{~min}$, centrifuged and the supernatant $(\mathrm{S})$ and pellet $(\mathrm{P})$ fractions were analyzed by SDS-PAGE. Note that BAR-PH (B-C), but not BAR-PH ${ }^{\mathrm{G}}$ or 32 -centaurin BAR-PH $\left(\mathrm{BARPH}^{\mathrm{B}}\right)(\mathrm{C})$, specifically recruits the $\mathrm{GAP}^{\mathrm{O}}$ to the liposomes and that $\mathrm{GAP}^{\mathrm{O}}$ does not inhibit membrane binding of the $\mathrm{BAR}-\mathrm{PH}^{\mathrm{O}}$ domains in trans (C) or cis (D). (E) Quantification of experiments as shown in (D) using densitometry $(n=4)$. The histogram shows percent bound protein, calculated as amount of protein in the pellet divided by the sum of protein in the supernatant and pellet. Error bars represents S.D. (F) Membrane tubulation by BAR-PH-GAP ${ }^{\mathrm{O}}$. Electron micrograph of liposomes incubated in the presence (upper panel) or absence (lower panel) of protein. Note the lipid tubule created from spherical liposomes by the addition of BAR-PH-GAP $(15 \mu \mathrm{M})$; scale bar $=0.1 \mu \mathrm{m}$. (G) Confocal micrograph of HeLa cell expressing myc-tagged OPHN1 BAR-PH-GAP. Scale bar $=10 \mu \mathrm{m}$. 
Figure 4 Conceptual models for BAR/GAP interaction of the GRAF protein family. Possible and probable binding modes of how the BAR domain of GRAF1 or OPHN1 binds to the GAP domain and inhibits its activity towards Rho protein (A) is illustrated schematically (B, C; see text for details). Dashed square indicates the membrane binding region at the reverse site. 

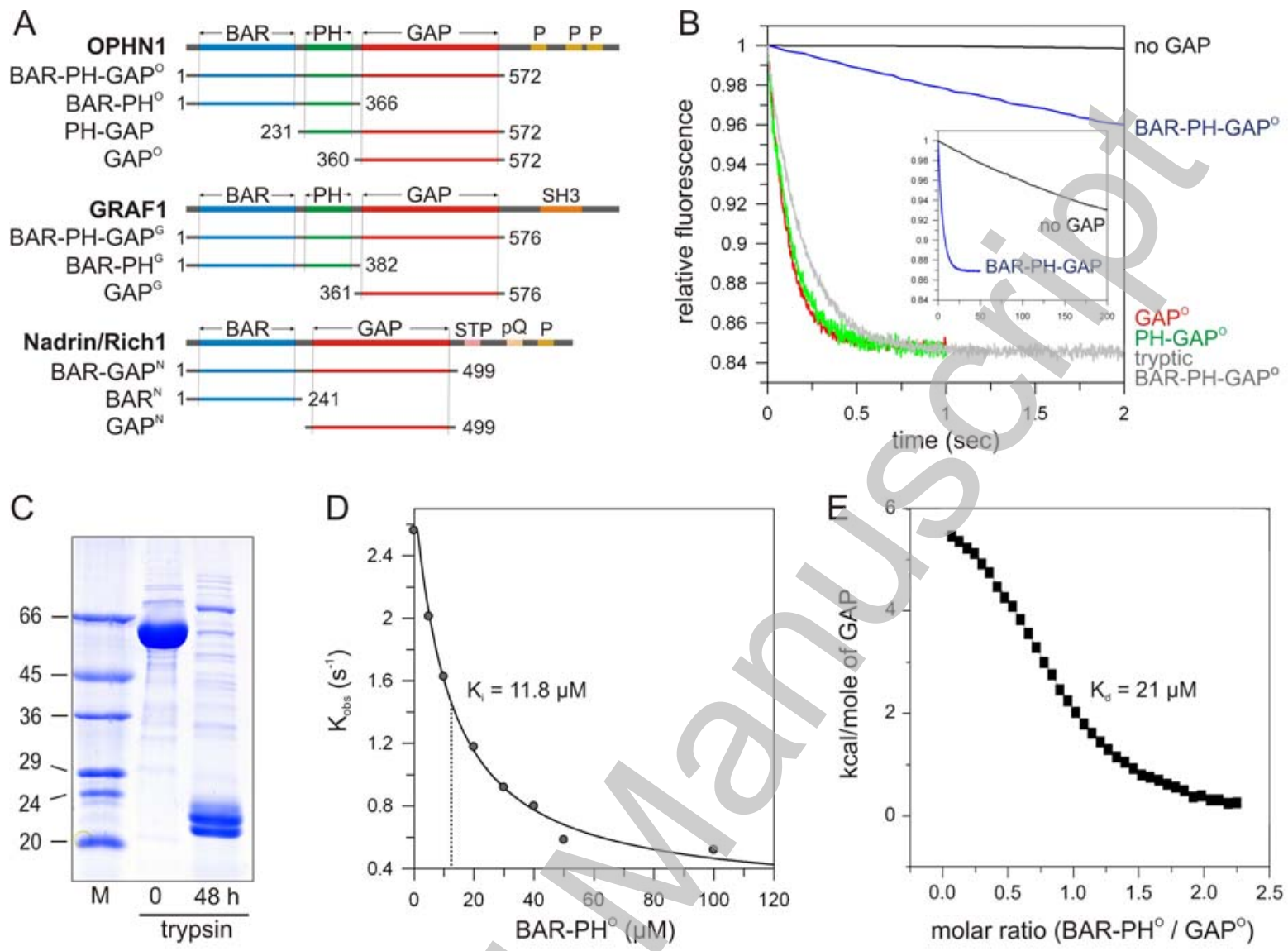

Eberth et al., Figure 1

Licenced copy. Copying is not permitted, except with prior permission and as allowed by law. (C) 2008 The Authors Journal compilation (C) 2008 Biochemical Society 

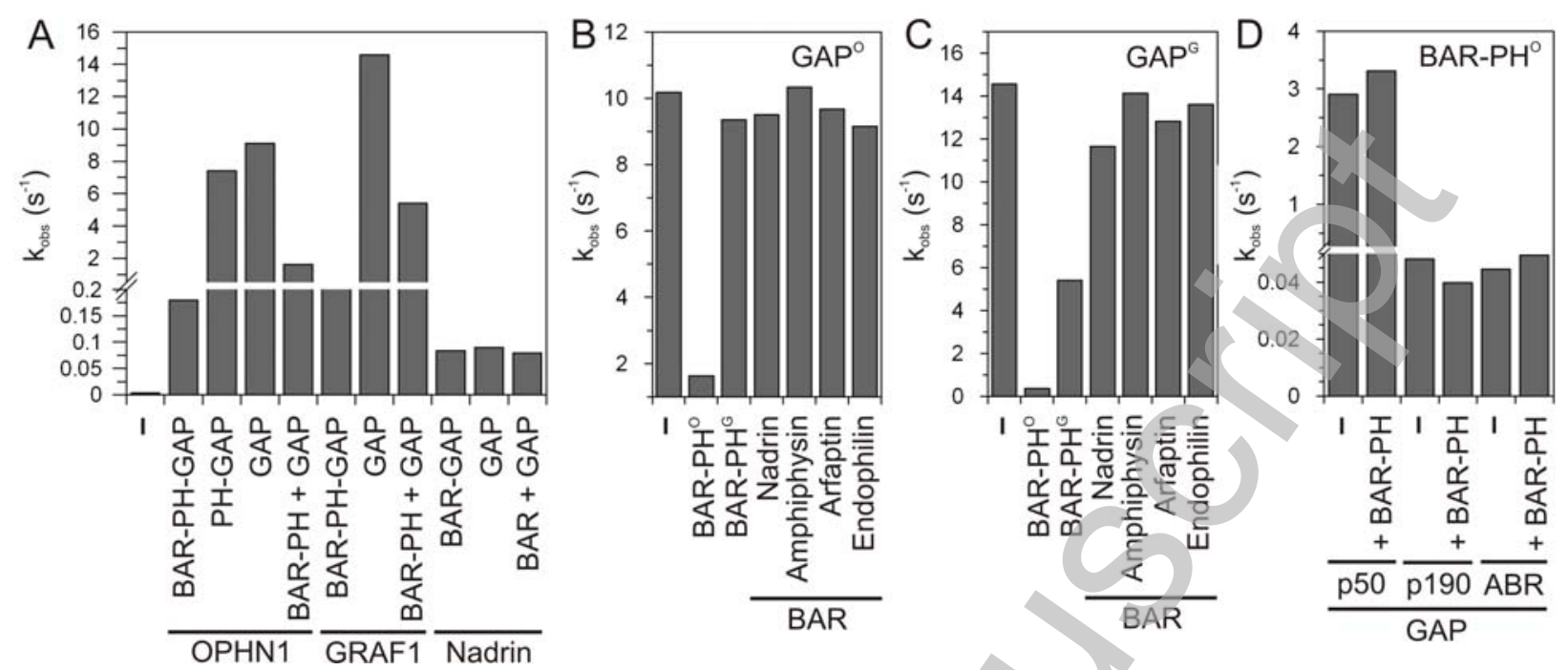

Eberth et al., Figure 2 
Biochemical Journal Immediate Publication. Published on 27 Oct 2008 as manuscript BJ20081535
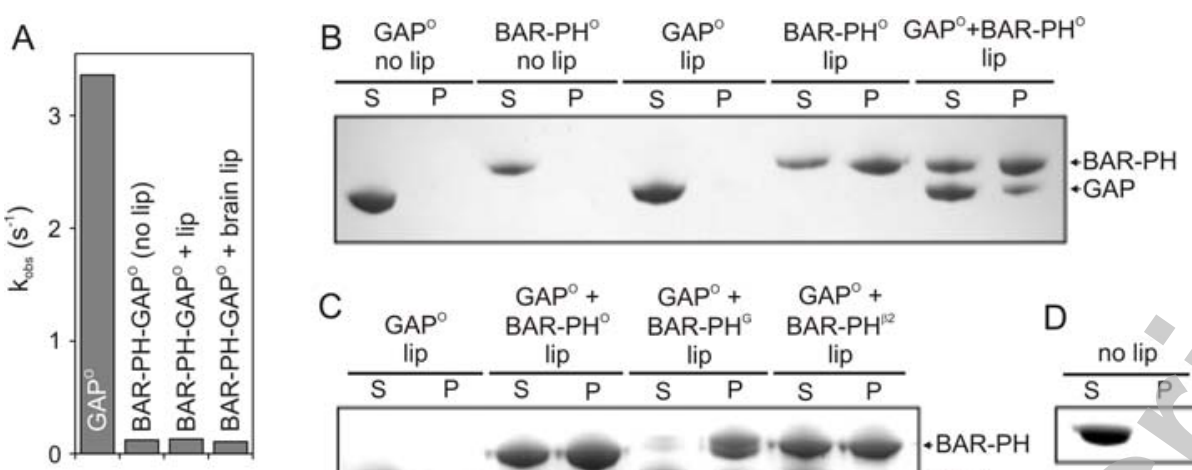

$\begin{array}{llrl}\mathrm{C}_{\text {GAP }}^{\circ} & \mathrm{GAP}^{\circ}+ & \mathrm{GAP}^{\circ}+ & \mathrm{GAP}^{\circ}+ \\ \mathrm{BAR}^{\circ}-\mathrm{PH}^{\circ} & \mathrm{BAR}^{\circ}-\mathrm{PH}^{\circ 2}\end{array}$

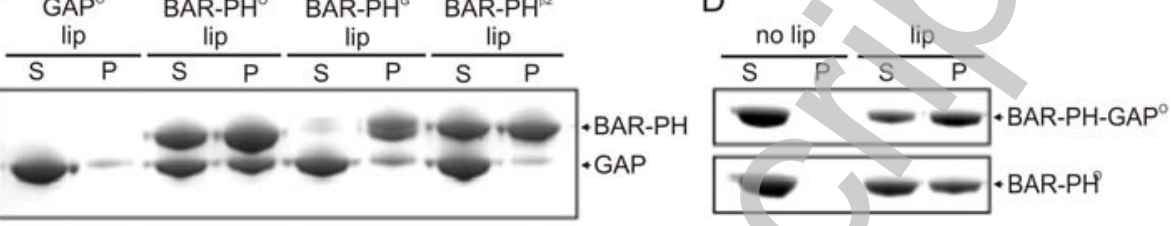

$E$

$\mathrm{F}$
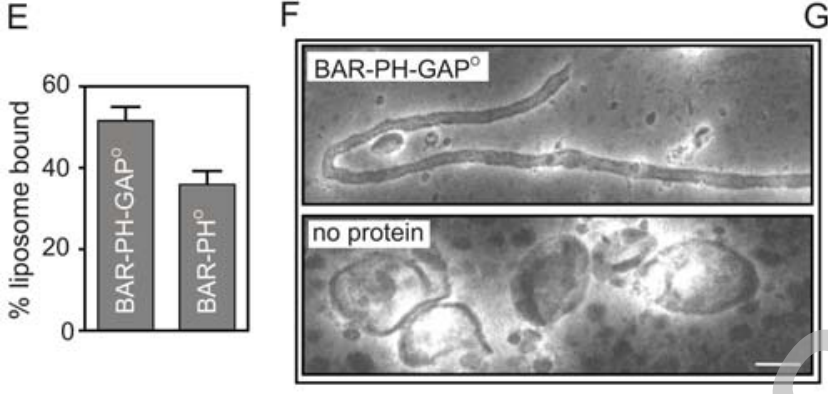

G

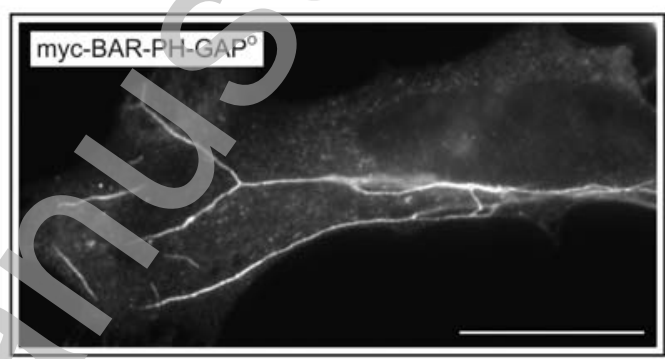

Eberth et al., Figure 3 


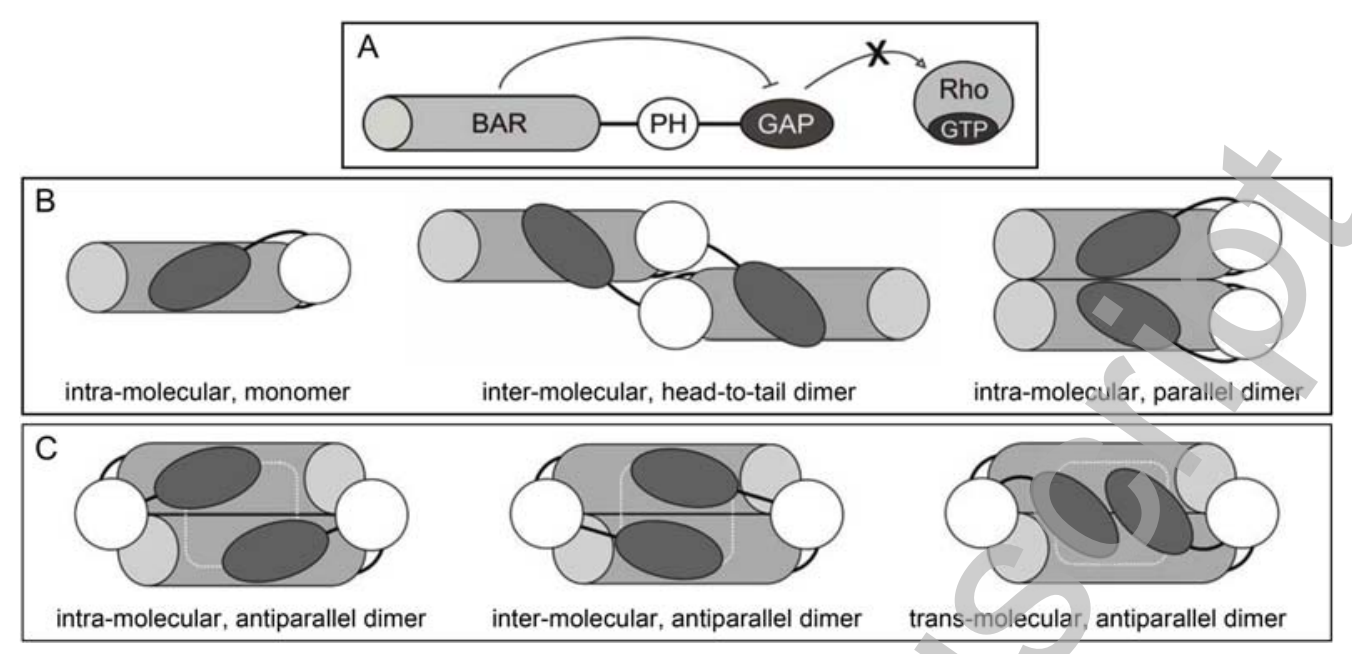

Eberth et al., Figure 4

Licenced copy. Copying is not permitted, except with prior permission and as allowed by law. (C) 2008 The Authors Journal compilation (c) 2008 Biochemical Society 